\title{
Loss of the Weight of a Rotor with Horizontal Axis of Rotation
}

\author{
A. L. Dmitriev ${ }^{1}$, N. N. Chesnokov $^{2} \&$ E. M. Nikushchenko ${ }^{1}$ \\ ${ }^{1}$ Baltic State Technical University "Voenmeh", St. Petersburg, Russia \\ ${ }^{2}$ LTD "Sartogosm”, St. Petersburg, Russia \\ Correspondence: A. L. Dmitriev, Baltic State Technical University "Voenmeh", St. Petersburg, Russia. E-mail: \\ alex@dmitriyev.ru
}

Received: December 22, 2018

Accepted: January 10, 2019

Online Published: January 29, 2019

doi:10.5539/apr.v11n1p79

URL: http://dx.doi.org/10.5539/apr.v11n1p79

\begin{abstract}
Concise description of results of exact weighing of mechanical rotor with the horizontal axis of rotation during "spinning" - with slowly diminishing speed of rotation. Reduction of the weight of a rotor with frequency of rotation of 350-375 Hz is in line with earlier noted oscillations of acceleration of such rotor's freefall. Observed effect of weight loss is probably defined by characteristics of interactions of accelerated moving bodies with variable gravitational field of the Earth
\end{abstract}

Keywords: gravitation, weight, rotor

Movement of mass point in a circle is a superposition of two phase shifted linear vibrations along orthogonal axes of coordinates located in the plane of rotation. Such test body fluctuates with variable (sinusoidal) acceleration characterized by an infinite set of derivatives multiplied by the frequency of rotation. Intricate accelerated movement of mass point along the vertical defines characteristics of its interaction with gravitational field of the Earth, which also causes some anomalies observed during freefall as well as during weighing of mechanical oscillator (Dmitriev, Nikushchenko, \& Bulgakova, 2010; Dmitriev, 2011). Outlined characteristics, considered in regards to thermal movement of micorparticles of the body, are caused by experimentally observed negative temperature dependence of the physical bodies and phenomenon of pushing of plasma in gravitational field (Dmitriev \& Bulgakova, 2013; Dmitriev \& Nikushchenko, 2016).

Below you may see results of weighing of a container with rotor of aviation mechanical gyroscope with horizontally oriented axis of rotation. Container with rotor installed inside (mass 986. $290 \mathrm{~g}$ ) is presented on Figure 1.

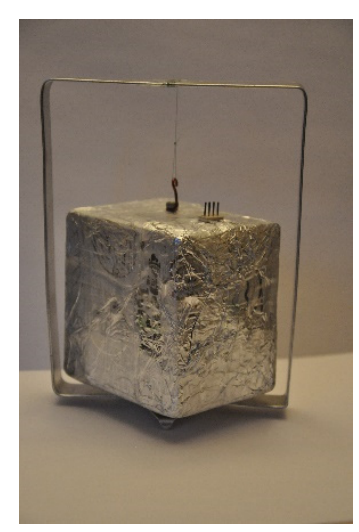

Figure 1. Container

In order to minimize impact on measurement of outer magnetic, electric and acoustic interferences, walls of container were made of permalloy protected by thermo- and soundproof cover. Container is hung in a light frame installed on the platform of Sartorius CC50 comparator with the thin nylon thread. Such positioning of weighed object eliminates slow precession of gyroscope on the scales platform. 
At the beginning on an experiment gyroscope is connected to the source of alternating current. For the duration of three minutes the rotor is spinning to a maximum frequency of rotation of $400 \mathrm{~Hz}$ and then the frame with hanging rotor is installed in comparator. During 21-22 minute rotor spinning, the frequency steadily decreases according to exponential law (Figure 2).

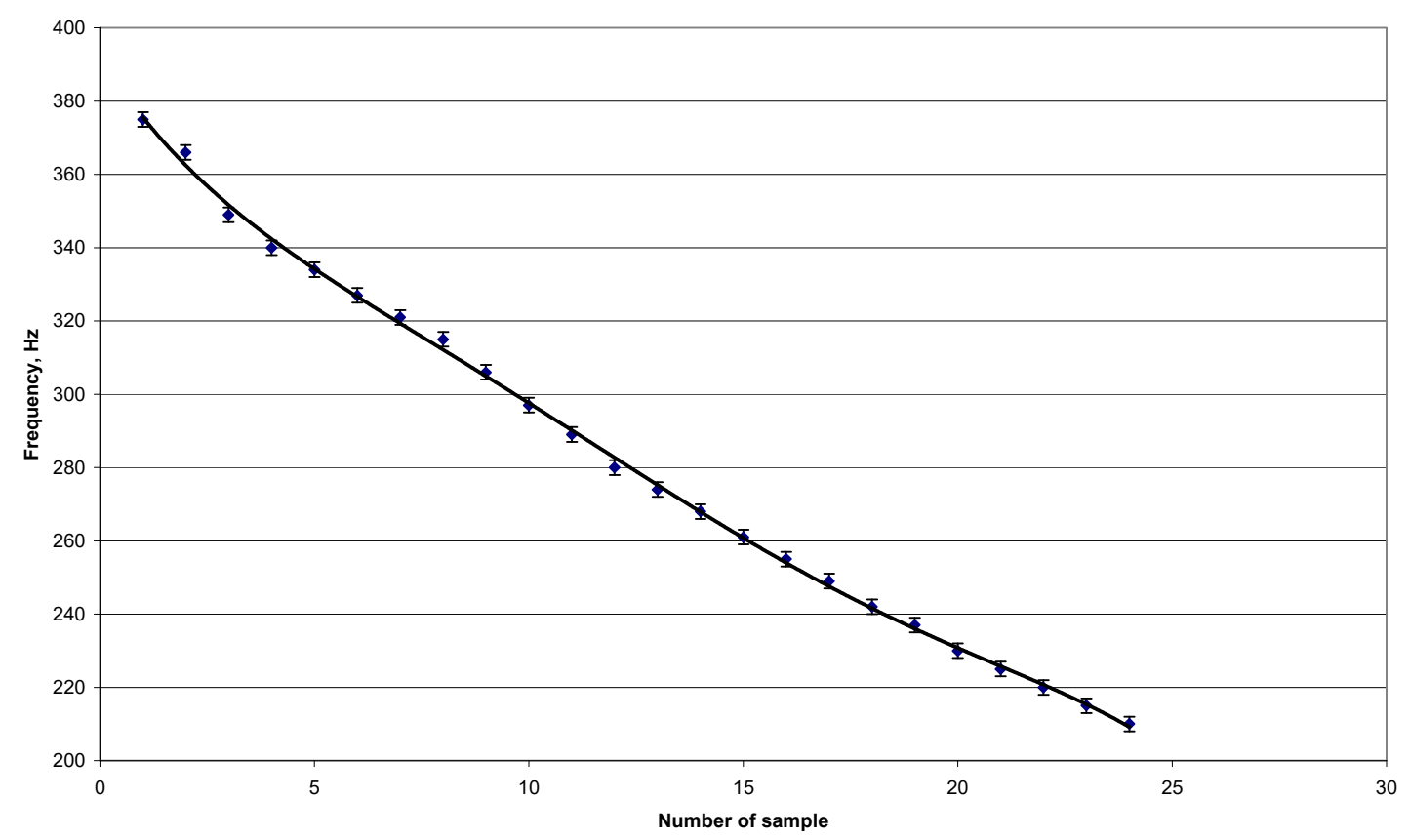

Figure 2. Time dependence of rotation frequency. Period of sample $15 \mathrm{~s}$

Comparator's readings were taken every $15 \mathrm{~s}$.

Example of typical time dependence of measured mass of container is shown on Figure 3.

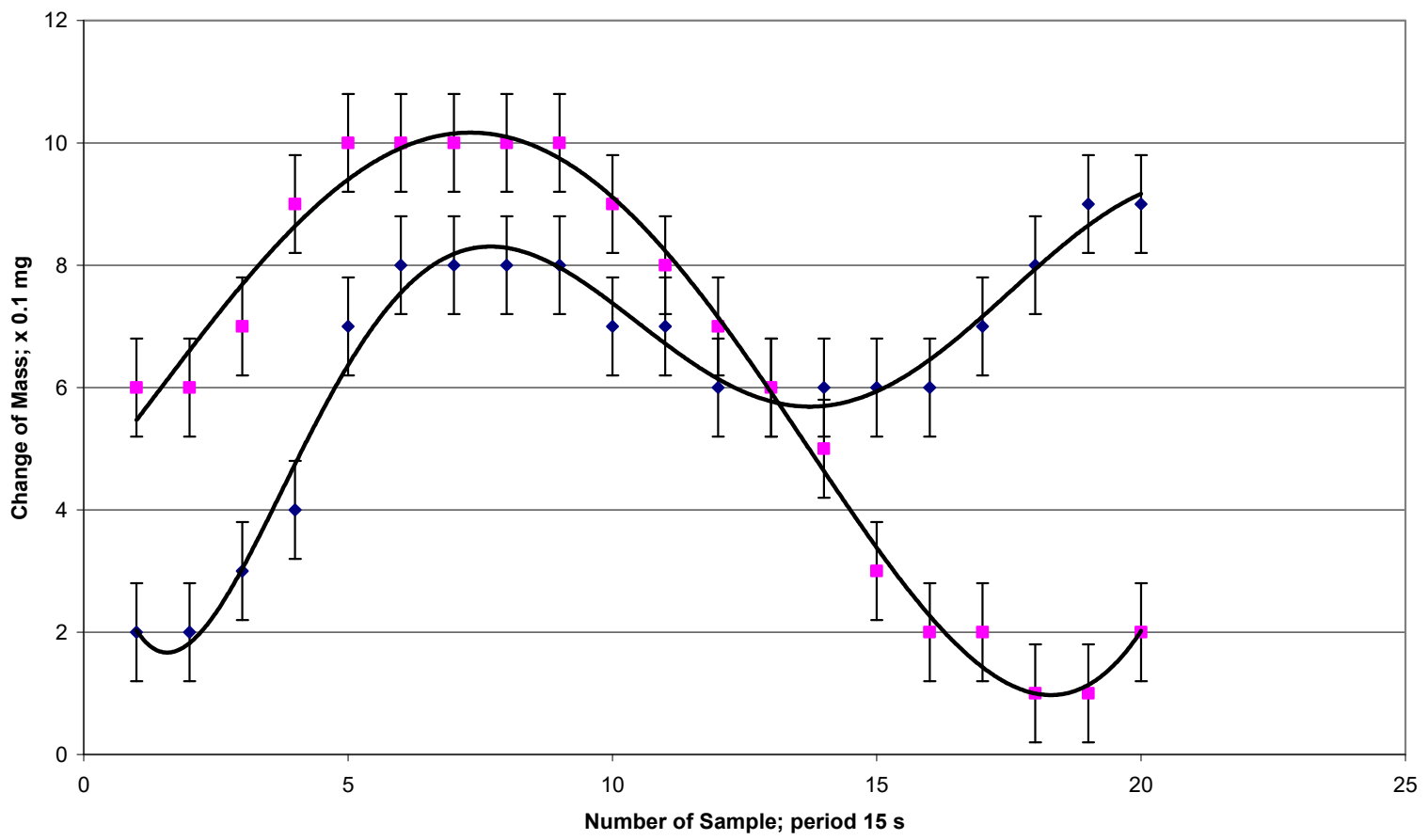

Figure 3. Typical examples of time-dependence of rotor mass 
At the start of measurements, during highest speeds of rotor rotation, the weight (mass) of container usually increased by $0.40-0.60 \mathrm{mg}$ and then decreased. Later on slow temperature drifting and random fluctuations of comparator readings were observed.

General characteristics of observed dependency of the mass of container, especially during initial stage of measurements, are in line with earlier measured frequency dependency of acceleration of freefall of mechanical rotor with horizontal axis of rotation shown on (Dmitriev, 2011).

Experiment confirms the fact of decrease of the weight of mechanical rotor with horizontal axis of rotation with frequency of rotation in the range of 350-375 Hz. Possible physical cause of such effect are small fluctuations (fluctuations in sound range of frequency) of intensity of gravitational field of the Earth, caused by geophysical processes in its volume, as well as influence of outer astrophysical factors.

\section{References}

Dmitriev, A. L. (2011). Frequency Dependence of Rotor's Free Falling Acceleration and Inequality of Inertial and Gravity Masses. arXiv preprint arXiv:1101.4678.

Dmitriev, A. L., \& Bulgakova, S. A. (2013, July). Negative Temperature Dependence of a Gravity-A Reality. In Proceedings of World Academy of Science, Engineering and Technology (No. 79, pp. 1560-1565). World Academy of Science, Engineering and Technology (WASET).

Dmitriev, A. L., \& Nikushchenko, E. M. (2016). Expulsion of Plasma in A Gravity Field. Applied Physics Research, 8(2), 38-39.

Dmitriev, A. L., Nikushchenko, E. M., \& Bulgakova, S. A. (2010, January). Dynamic Weighing Experiments-The Way to New Physics of Gravitation. In AIP Conference Proceedings (Vol. 1208, No. 1, pp. 237-246). AIP.

\section{Copyrights}

Copyright for this article is retained by the author(s), with first publication rights granted to the journal.

This is an open-access article distributed under the terms and conditions of the Creative Commons Attribution license (http://creativecommons.org/licenses/by/4.0/). 